\begin{tabular}{|c|c|c|}
\hline 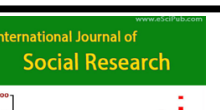 & & 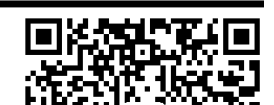 \\
\hline 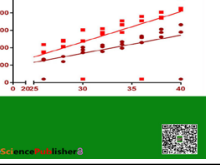 & $\begin{array}{l}\text { International Journal or Soclal Researcn } \\
\qquad \text { (ISSN:2576-5531) }\end{array}$ & 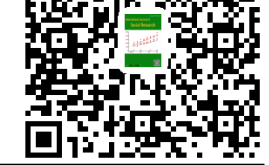 \\
\hline
\end{tabular}

\title{
Second Language Acquisition and Learning: Rethinking the Pedagogical Applicability of Stephen Krashen's Monitor Model
}

\author{
Mzamani J Maluleke ${ }^{1^{*}}, \quad$ Aleck Mapindani ${ }^{2}$ \\ ${ }^{1}$ University of Venda. ${ }^{2}$ Greater Zimbabwe University
}

\begin{abstract}
The monitor model, being one of its kind postulating the rigorous process taken by learners of second language, has since its inception in 1977, stirred sterile debates the globe over. Since then, Krashen has been rethinking and expanding his hypothetical acquisition notions, improve the applicability of his theory. The model has not been becoming, and it therefore faces disapproval on the basis of its failure to be tested empirically and, at some points, its contrast to Krashen's earlier perceptions on both first and second language acquisition. In this paper, the writers deliberate upon Krashen's monitor model, its tenets as well as the various ways in which it impacts, either negatively or positively upon educational teaching and learning.
\end{abstract}

*Correspondence to Author:

Mzamani J Maluleke

University of Venda.

Keywords: Acquisition; Rigorous process; Stephen Krashen;

Keywords: Acquisition; Rigorous process; Stephen Krashen; Monitor model; Hypothetical acquisition; Language Acquisition Device

How to cite this article:

Mzamani J Maluleke, Aleck Mapindani. Second Language Acquisition and Learning: Rethinking the Pedagogical Applicability of Stephen Krashen's Monitor Mode. International Journal of Social Research, 2020; $4: 50$.

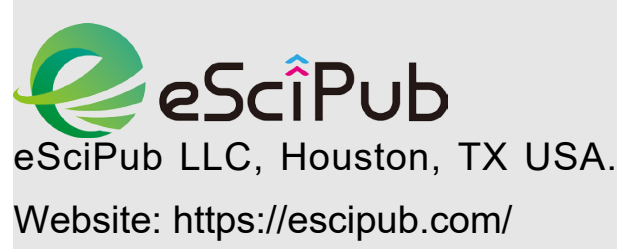




\section{Introduction}

Stephen Krashen's monitor model which was first proposed in 1977 is still a topical issue in the field of second language acquisition (SLA). He postulates that learning a second language can be divided into two kinds: acquisition and learning. Acquisition occurs at a subconscious level where learners are exposed to language forms which they intuitively attain its pattern whereas learning is a conscious acquisition of knowledge of a second language focusing on its form and structure. He regards acquisition as a subconscious process and learning as a conscious process. Krashen (1982) further maintains that explicit learning in a second language does not result in acquisition. Tricomi (1986) praises Krashen for making meaningful contribution to the study of second language through his distinction between acquired and learned competences. Krashen's contribution to second language acquisition has been highly acclaimed, however, some researcher identified several pitfalls which need to be clarified for the model to be applied in all situations.

Hardly a year after its initial publication, Mclaughlin (1978) criticized Krashen's model by arguing that "the evidence is too fragile to support the theoretical edifice that has been constructed" as the theory failed to clearly justify the distinction between acquisition and learning processes. He further indicated that "Krashen has not defined his terms with enough precision" which resulted in the empirical theory being propounded not clear in its precision (1987:56). Another scratching attack was unleashed by Gregg (1984) who posits that the evidence that Krashen provides is insufficient and cannot apply to all situations. Cook (1993) comments that Krashen's model sounds sensible but its practicability can be verified. Other researchers point out that there is a correlation between how learners acquire explicit and implicit knowledge which is contrary to Krashen's postulation.

Ellis (2004: 234) argues that “Krashen's position has come under considerable attack" because of his claim that there is no transfer of knowledge from explicit to implicit learning. Krashen's claim means that thorough attention needs to be taken when implementing the theory especially in countries such as South Africa and Zimbabwe where learners are not in immersion programmes and hardly come into contact with native speakers of English. Participation in class is very low as learners do not have the necessary vocabulary to enable them to interact with their teachers.

Richard and Rodgers (2001) affirm that immersion programmes have proven to be effective for students learning a second language as teaching focuses on the content which the students are expected to acquire; this can be contrasted to students learning under different contexts as there are noticeable differences in the manner in which students acquire competence in their first (L1) and second languages (L2). Dascomb (2019) argued that instruction in first language is important in helping all learners acquire knowledge as they will be motivated to learn in the language they use on all purposes. Krashen (1985: 85) also agreed that students learning in immersion programmes acquire a second language better as they "are exposed to a great deal of the second language" than students learning under normal conditions. Swain (1995) writes that children learning French in immersion programmes failed to acquire adequate grammatical and sociolinguistic competence like native speakers. The findings highlight comprehensible input cannot help L2 students acquire proficiency in both oral and written production.

To validate his claims, Krashen wrote several books, journal articles and made conference presentations wherein he modified his initial claims and provide empirical evidence to support his assertion. In one of his latest articles, he argued that reading can be acquired through three different stages which are "hearing stories, doing a great deal of self-selected reading, followed by reading for our interest in our chosen specialization" (Krashen 2014: 1). He further opined that optimal input is more interesting and compelling as the acquirer became absorbed in reading a text hardly aware that it is not written in his /her first language. The debate on Krashen's hypo- 
theses of second language acquisition has been a continuous process which has spun for about four decades and continue to gain momentum. The current article, therefore, focusses on the impact of Krashen's model on learning situations where English is used as the medium of instruction despite it being a second language for the learners.

\section{Krashen's Monitor Model}

Krashen divided his monitor model into five interrelated hypotheses premised on the principles of universal grammar with its notion of language acquisition device (LAD). He made several claims and assumptions on how a second language can be acquired while making a distinction between learning and acquisition. He argued that grammar must not be taught at all and the teacher's role is to provide a conducive environment in class for students to acquire a second language in a meaningful way. To get to the depth of the language learning/acquisition dichotomy, the researchers have critically focused below on each of the five hypothesis and provided insight on the possibility of their application in learning a second language

\section{The Acquisition-Learning Hypothesis}

In his Acquisition-Learning Hypothesis, Krashen has pointed out that second language mastery for adults comes in two different ways. Firstly, mastery can be through language acquisition which he describes distinctively from the second way, language learning through exposure to comprehensible input. By acquisition, he describes the naturalistic manner in which adults either unconscious or subconsciously assimilate and incorporate components of a foreign language to enrich their linguistic competence. This means that speakers are concerned not with the form of their utterances but with the messages they convey and understand (Krashen 1981). This usually happens in situations where speakers find themselves immersed in linguistic communities where they are foreigners. This way of mastering a language, according to Krashen, is the same way as the one used by children when they acquire their first languages, an advantage naturally attainable in any human due to the presence of the Language Acquisition Device (LAD) (Zafar 2009). Krashen argues that in acquisition, proficiency is gained unconsciously, that is devoid of strained activity in trying to master the rules that govern the formalities of linguistic purity and correctness. Krashen (1981), basing his arguments on previously conducted researches, points out that error correction and explicit teaching of rules are not relevant to language acquisition (Brown and Hanlon, 1970; Brown, Cazden, and Bellugi, 1973).

In learning, the learners are obliged to undertake rigorous actions by striving to master the grammatical, syntactical, spelling accuracies and other necessary linguistic rubrics that forge the formalities of universally approved educational language mastery. In a sense, learners have to be conscious and be mindful of the learned language's rules of both its written and spoken forms. Where errors have been made, learners have to revisit their work, rectifying, mostly with the assistance of an experienced teacher or through rote learning process. Gregg (1984) gave a vivid example of how a student managed to acquire a working memory of Japanese verbs by memorizing the chart displayed in his textbook. This way of internalising language takes place in a classroom setting at schools where a target language is taught.

A critical investigation of Krashen's hypothesis reveals that both acquisition and learning are critical in gaining proficiency in any targeted second language: this means that they both serve instrumental roles in enhancing proficiency by learners of second languages. Some linguists like Chomsky (1975), however revealed that the LAD declines as a person grows old. This means that language acquisition operates sufficiently in children and it therefore follows that adults can be successfully exposed to learning a second language as opposed to acquisition. The Acquisition-Learning Hypothesis cannot be holistically applied if serving a pedagogical role as this is the major objective of its application. In any case, it is generally taken for granted that learning can better serve the purpose compared to acquisition (Marton 1990). 


\section{The Natural Order Hypothesis}

The second theory of language acquisition being the Natural Order Hypothesis, is credited to Corder (1967) by Krashen as the founder of the hypothesis. Ellis, Tanaka and Yamakazi (1994: 481) conducted an empirical study in an attempt to give clear evidence on vocabulary acquisition and concluded that different aspects of language "may not be acquired in the same way". In this theory, proficiency in the target language's grammatical structure is achieved in a predictable natural order, though it is argued, not all learners of a second language follow this prescribed course of linguistic acquisition (Zafar 2009). It is also observed that in acquiring grammatical structures, language learners tend to acquire some grammatical structures better and faster than others, and this happens without taking the participants' age, sex, ethnicity or first language into cognizance. The process occurs regardless of the first language of a learner, the age and conditions of exposure Bahrani (2011). It was noted, therefore that this theory operates only under language acquisition as opposed to Krashen's concept of language Learning (Zafar 2009 and Bahrani 2011).

In spite of learners' differences on the manner in which they acquire grammatical structures, teachers must play a meaningful role of nurturing and guiding them on how to use grammar rules effectively. Hinkel (2013) argues that teaching grammatical structures is essential for students who aspire to excel at tertiary level as they help them improve on the quality of the written text they produce. Hiver and Dörnyei (2015: 1) succinctly outline that "teachers are in charge of training the next generation of citizens, and have the ability to shape the course of their students' future" as a means to highlight the important role of teaching grammar rules. They found that acquisition on its own does not equip learners with the desired language skills.

Critics find this language acquisition hypothesis inadequate in that it gives minimal potential to language learners to gain proficiency in the target language. The exclusion of aided and instructional enhancement of language internali- sation becomes, in this hypothesis, a loophole in facilitating both a learner's linguistic competence and performance in the target language. This is especially where there are no instructors to moderate affective factors for acquisitional boosting. Seen this way, the hypothesis has minimum pedagogic impact in as far as the mastery of target second languages is concerned.

\section{The Monitor Model Hypothesis}

The Monitor Model the third of Krashen's hypotheses, is described as one of Krashen's centre of attention in his formulation of his theories. Krashen (1982) points out that the Monitor Hypothesis builds upon the Acquisition-Learning Hypothesis. In his explanations, acquisition is responsible for generating utterances but learning edits these generated utterances to make them meaningful and sensible. This means that second language learners can use the rules of grammar they have learnt to monitor their language production (Tricomi, 1986). The learned (monitor system) has to be activated and this calls for three contributory factors namely time, focus on form and knowledge of the rules that govern the target language, thus making the hypothesis complex and complex for testing in real life situations (Zafar 2009).

In the view of this hypothesis, learning under an experienced instructor is unfavourable in comparison to acquisition. In this manner, the theory deviates from the mission of pedagogical instruction where educational essence is realised in instilling knowledge to learners under the guidance of teachers. It further contradicts the notion of pedagogic grammar that "teaching is not only a matter of providing the learner with the right data at the right time, of teaching him how to learn, but of developing in him appropriate learning strategies and means of testing his hypothesis as well" as put forward by Corder (1973:133). Ellis (2010) demonstrated the applicability of SLA to language pedagogy which found to be an important component of second language acquisition. Thus, the idea that acquiring a language is at loggerheads with the assumed value of education, and it therefore dissuades and blocks the intentions of pedagogic realisations in learn- 
ing environments.

The monitor theory also made distinction between three types of language learners: Optimal Monitor users, monitor underusers, and Monitor overusers (Krashen, 2003). The three types bear witness to the fact that learners have individual differences in the manner in which they acquire a second language. To cater for different types of language learners, Butzmann (2009) suggest that there must be a compartmentalization of declarative knowledge and procedural knowledge. Language teachers must play an active part in explaining to the students the role of grammatical rule and how to apply them in both speaking and writing.

\section{The Input Hypothesis}

The Input Hypothesis states that second language learners acquire language from level 1: a level at which they know at least their native language and nothing on the target language. In order to achieve comprehensible input, acquirers have to be introduced to language structures that are a little above what they already know or which is a step beyond the structures they have already acquired (Tricomi, 1986). Learners will then use the current linguistic competence of their native languages to master linguistic components of targeted second languages. Krashen clarifies his theory by devising a formula " $\mathrm{i}+1$ " wherein i refers to the language learner's comprehensible input and +1 refers to the next level of language achievement which is not far from the current level. Exposing them to language structures that are far above their current linguistic knowledge may result in impaired concentration and acquisition. Quoted in Bahrani (2011) Gitsaki (1998) and Wilson (2000) point out that progression can also be achieved by context or extralinguistic information. It is necessary for language learners to be given an initial silenced period during which they can build up acquired competency in the language before beginning to produce it (Bahrani 2011). The theory also failed to clarify how can teachers practically determine each language learner's present level of "i" in order to provide the essential " +1 "in an overcrowded class as may be the case in some language situations.

The Input Hypothesis assists in the acquisition of second language components in that teachers (other second language native speakers included) will make sure they reduce their verbal linguistic complexity to the level that can be easily understood by learners. Payne (2011) suggests that teachers must constantly repeat vocabulary of the second language and also request students to repeat the vocabulary a number of times so that learners can get acquainted with the new language. This makes communication possible between the two parties and therefore has a positive bearing on educational attainment and delivery between teachers and language learners. Long (1996: 452) asserts that conversational interaction plays an important role in helping $\mathrm{L} 2$ learners acquire verbal fluency as it "connects input, internal learner capacities and particularly selective attention, and output in productive ways". This assertion negates Krashen hypothesis that comprehensible input is the only means which can help learners acquire an L2.

McLaughlin (1991) commends the role of input in language learning but further notes that input alone is not essential in empowering learners with all the rules of grammar. Gass and Selinker (1997) concur by indicating that second language learners' comprehensible input should not be limited to the range of " $i+1$ " formula but second language learners should be exposed to a large amount of input which they can notice through its frequency, affect, prior knowledge and attention. Additionally, Lightbrown and Spada (1999) hint that learners acquire proficiency in a second language when they constantly interact with more advanced speakers of the target language who include teachers and peers who speak the language fluently. Shechter (2018) supports the teaching of grammar rules and structures to help English foreign language learners acquire competence in English as the medium of instruction in Israel. The teaching of grammar is therefore important in supplementing the input hypothesis and help learners improve their communication skills. 


\section{The Affective Filter Hypothesis}

In the Affective Filter Hypothesis, Krashen claims that there are three factors: self-confidence, motivation and anxiety that play pivotal roles in the acquisition of a second language. He further indicates that these factors may either hinder or enhance second language acquisition. Abukhattala (2013) notes that the affective filter serves as a gate that controls the amount of input which must reach the LAD and discard all unnecessary information. Thus, for a language learner to easily acquire a second language, factors like motivation, self-confidence and anxiety must be at acceptable levels. Bahrani (2011) disputes this claim by elaborating that "low motivation, low self-esteem, and debilitating anxiety can combine to 'raise' the affective filter and form a mental block that prevents comprehensible input from being used for acquisition".

Bahrani (2011) argues that a second language teacher's major role (in a classroom context) would be to strive towards the maintenance of appropriate levels of affective factors for conducive learning. Brown (2007) maintains that there are numerous instances in which adults acquire a native-like proficiency and that the three factors are not the only means to fast track second language acquisition. In this light, the Affective Filter Hypothesis' plays a major pedagogic role in helping both teachers and students in terms of what attitudes to take in order to raise learners' affective filters to desired acquisition levels.

\section{Discussion and implications}

For about forty years, Krashen has been through an excruciating journey of conducting empirical studies to convince his critics about the applicability of his model. He has written several books and journal article, thus making additions and expansions to consolidate his model. Wheller (2003) confirms that "Stephen Krashen has written more than 250 publications, including 10 books. He has won several awards for his writings and been invited to speak (more than 300 times by one count) at a great number of major conferences" which clearly indicates than he has made extensive attempt to justify his claims. In addition, numerous researchers have written articles and books in support of Krashen's model. VanPattern and William (2007) argue that the monitor model has contributed in shaping language policies in developed countries such as the USA and Britain where grammar teaching was rejected from the late 1970s until the early 1990s. These countries rejected grammar teaching on the basis of Krashen's postulation that language is acquired implicitly from adequate exposure to the target language and that learned competence and acquired competence develop differently. Certain inaccuracies in the manner in which the model is presented and implemented, however, has invited criticism from researchers who provided counter claims and question the theory's applicability. Graciá (2009) contends that adequate bilingual development can only be achieved by extracting what is feasible in one theory and combine with what is practical in another than to rely on one theory.

In the first hypothesis (the acquisition-learning), Krashen alleges that there is no distinction in the manner in which adults acquire a second languages and how children acquire their primary languages. Schachter (1988) negates the claim by scrutinizing the relationship between second language acquisition and universal grammar. She therefore proposed four major differences: completeness, equipotentiality, previous knowledge and fossilization, which should be explored in terms of second language acquisition by adults and first language acquisition by children. The aforementioned differences indicate that there is no resemblance between $L 2$ acquisition by adults and L1 acquisition by children. Krashen, in his theory had vehemently criticised the teaching of grammar which he regards as a waste of learners' time preventing them from engaging in fruitful communication which spontaneously leads to acquisition. Krashen (2012) argues that learners from poor families can develop academic proficiency through spectacular use of the library than receiving instruction on grammar rules. Cho and Krashen (2019) voiced their frustration that after many decades of demonstrating evidence about the power of reading as backbone of natural language 
acquisition and comprehensible input, policy makers and curriculum specialist still promote conscious learning of grammar and its rules.

In the natural order hypothesis, Krashen (1981) maintains that students acquire structural items in a second language in a predictable order. The natural order hypothesis entails that when learning the rules of language, some grammatical structures can be easily acquired than others. Gregg (1984) pinpoints that Krashen's (1981) natural order hypothesis focused on the acquisition of English morphemes by L2 students without testing other linguistic features such as phonology, syntax, semantics and pragmatics. Martin and Ellis (2012) analysed vocabulary learning and grammar learning and found that their combination is essential to help adult learners succeed learning a second language. Abukhattala (2013) added that this hypothesis should "include more recycling" of printed material to ensure that structures that students receive late are also catered. This further proved that Krashen's (1981) focus on morphemes as determinants of the natural order of acquiring a second language, hence, is flawed which makes challenging for the hypothesis to be implemented to all second language students learning in different environments.

Krashen's monitor hypothesis is the most controversial one as it gives more priority to acquired knowledge at the expense of learned one. The acquisition system plays a major role of initiating the utterance while the learning system only play the role of the 'monitor' or 'editor' under three specific conditions: time, correctness and rule. Ellis (2004) affirms that explicit knowledge contributes indirectly to how a learner acquires implicit knowledge which contradicts Krashen's notion of referring to the acquired system as serving as just a monitor. Zafar (2009:142) also criticizes the monitor model "for being poorly supported by empirical evidence" while making extreme claims on the futility of learning grammar rules.

The input hypothesis has drawn a lot of criticism due to the proposed formula which Krashen claims determine the level of acquisition. Payne
(2011) conducted a small-scale study in South Yorkshire to evaluate how learners acquire ' $i+1$ ' through comprehensible input. She noticed that the comprehensible input does not clearly spell out how different learners in a class attain the +1 thus rendering the theory problematic. Abukhattala (2013) avers that the issue of silent period further complicates the situation because teachers work under strict conditions where they are supposed to cover an entire syllabus before learners sit for final examination. More importantly, input alone cannot sufficiently help learners acquire L2 as they are supposed to process and practice the transmitted information through practice (Alahmadi, 2019). The situation is worse in countries such as South Africa and Zimbabwe where students only speak the L2 (English) in class where it is used as the medium of instruction and spend most of their time conversing in their $\mathrm{L} 1$.

In the Affective filter hypothesis, there is no serious issue to contend because one of the requirements for a language teacher is to have adequate control of affective factors. The three variables: self-confidence, anxiety and motivation are essential ingredients which can help students acquire language skills. Brown (2007), however cautions that there are more variables which adults utilize to acquire native-like proficiency than the three which Krashen has proposed. Although there is other variable which are essential in second language acquisition, the affective filter hypothesis is highly commended. Tricomi (1986: 62) remarks that "Krashen's work provides a valuable tool that can be used both to analyse and evaluate a number of pedagogical practices" although she acknowledges that there are inconsistencies in Krashen's theory. It is important to note that the affective filter acts like a valve which regulates acquisition of knowledge under conducive environment.

Therefore, each of the five hypotheses which Krashen has proposed must be reviewed carefully making additions and expansions in an effort to tighten it before it can be adopted for use in an SLA. Saville-Troike (2006) avers that Krashen's monitor model has been a source of 
influence on language teaching in the United States of America in the 1980s and 1990s but "[the] pendulum has since begun to swing back in the opposite direction, with formal grammar teaching increasingly being introduced". This confirm that linguists and language policy planners have reviewed the issue of grammar acquisition and realize that English second language students need explicit explanation of grammatical structures even when learning in immersion programmes.

Education planners in Africa and other counties where English is the second language need to take a proactive role in carefully planning how grammar lessons can be implemented to empower students to acquire second language skills. For example, Mutekwa (2013) challenged all stakeholders involved in education in Zimbabwe to play an active role in ensuring that the Communicative Approach is successfully implemented. Poudel (2019) highlights the challenges which affects learners in Nepal where parents, communities and private sector promotes the use of English as the medium of instruction and national indigenous languages play a secondary role. On the hand, Edu-Baundoh (2016) proposed that language policies in post-colonial states such as Ghana need to be reconsidered to enable indigenous languages to coexist equally with former colonial languages. The situation in South Africa is not an exception because majority of learners struggle to acquire average level of proficiency in English which is the medium of instruction in most schools as they use the communicative approach to language teaching and ignore teaching grammar.

\section{Conclusion}

In this paper, the writers attempted to give an assessment of Krashen's Monitor Model and how it operates within the parameters of education. Thus, a critical review of his five hypotheses, purged from within the condensed Monitor Model, has proven to be an application complexity and controversy that no linguistic scholar has yet outdebated. Some, if not most of the discussed hypotheses would prove otherwise applicable, if not semi-applicable in pedagogic relevance. In some instances, the assumptions appear far-fetched and irrelevant if not empirically untestable. Marton (1990) succinctly avers that Krashen's hypothesis is anti-pedagogical and difficult to implement. From these words of Marton (1990) the essence of pedagogy and its value resides in the conviction that formal teaching and learning, should be superior to trial and error learning in a natural environment, otherwise sending our children to schools could be questionable.

Krashen, monitor model has seriously influenced the manner in which language is taught in South Africa where the main focus in on communication competence. Language policy specialists must consider including teaching grammatical structure even when using the Communicative Approach to language teaching. South African learners with limited English-language proficiency performed badly during the TIMSS 2003 contest compared to those with better Englishlanguage proficiency (Demspter \& Reddy, 2007) and the trend seems to continue. It is, thus, not surprising that majority of learners who pass grade 12 with a university exemption struggle to write coherent essays at tertiary level as they lack knowledge on grammatical structures. A similar situation is reported by Mutekwa (2013) who proposed that a local version of communicative approach need to be implemented in Zimbabwe to cater for local learners than to rely on the success of international studies.

Krashen's claims in the monitor model negatively impacts the manners in which teachers instructs language skills to L2 students. Latifi et al. (2013: 231) give credit to Krashen's model by highlighting that: "[No] theory can be flawless and without any deficiency", thus, the monitor model is being implemented in some schools with its deficiencies and many teachers have given different results about its effectiveness. The dichotomy between acquisition and learning is very important as it helps us understand the concept of bilingual development (Graciá, 2009). It is imperative to note that the field of SLA is a broad one and no single model can address all areas to assist adult ESL students acquire 
native-like proficiency. Ellis (2010) also cautions that the field of SLA is very broad and have many challenges which cannot be addressed by models used in L1 acquisition. Moreover, cultural differences in the structure of academic rhetoric makes it difficult for learners to easily acquire proficiency in an L2 without rigorous learning of grammar. Language policy planners, especially in African countries should make intensive investigation than to implement SLA theories which have numerous challenges that affect students which such concepts were supposed to help.

In a nutshell, the field of SLA is still a fertile ground which needs to be further explored as there is no single theory or hypothesis which adequately addresses the needs of second language users. There is also paucity of empirical evidence from studies conducted on the effectiveness of the monitor model in teaching English second language students. This article has shed some light on the challenges which can be encountered if the monitor model is implemented on its own; additionally, it highlights the contribution of other L2 theories or models to determine if they can be used simultaneously with the monitor model.

\section{REFERENCES}

[1] Abukhattala, I. (2013) Krashen's Five Proposals on Language Learning: Are they Valid in Libyan EFL Classes. English Language Teaching, 6 (1): 128-131.

[2] Alahmadi, N.S. (2019) The Role of input in Second Language Acquisition: An Overview of Four Theories. Bulletin of Advanced English Studies, 3(2), 70-78.

[3] Bahrani, T. (2011) The Implications of the Monitor Theory for Foreign Language Teaching. Asian Social Science, 7 (10): $281-284$.

[4] Brown, H.D. (2007) Principles of language learning and teaching ( $5^{\text {th }}$ edn.). New York: Addison Wesley Longman.

[5] Butzkamm, W. (2009) The language acquisition mystique: tried and found wanting. ForumSprache, 2: $83-93$.

[6] Cho, K.S and Krashen, S. (2019) Why don't we take advantage of the power and pleasure of reading. Language and Language Teaching, 8(1),38-42.

[7] Chomsky, N. (1975) Reflections on Language. New York: Pantheon.

[8] Corder, S.P. (1967) The significance of learner's errors. International Review of Applied Linguis-

tics, 11: 13-28.

https://doi.org/10.1515/iral.1967.5.1-4.161.

[9] Corder, S.P. (1973) Pedagogic Grammar. In W.R. Rutherford \& M.S. Smith (eds.), Grammar and Second Language Teaching, (pp. 123 145). New York: Newbury House.

[10] Dempster E.R. and Reddy, V. 2007. Item readability and science achievement in TIMMS 2003 in South Africa. Science Education, 91(6), 906-925. https://www.re-

searchgate.net/deref/http\%3A\%2F\%2Fdx.doi.or g\%2F10.1002\%2Fsce.20225

[11]Dascomb, A.E. (2019) Language Education Policy in Developing Nations from Colinisation to postcolonisation, International Journal of Society, Culture and Language, 7(1), 16-26.

[12] Edu-Baundoh, D.F. (2016) Identity and Representation Through Language in Ghana: The Postcolonial Self and the Other. International Journal of Society, Culture and Language, 4(1), 34-44.

[13] Ellis, R. (2004). The definition and measurement of L2 explicit knowledge. Language Learning, 54, 2: 227 - 275. https://doi.org/10.1111/j.14679922.2004.00255.x

[14]Ellis, R.; Tanaka, Y. and Yamakazi, A. (1994) Classroom interaction, comprehension and the acquisition of $\mathrm{L} 2$ word meanings. Language Learning, 44(3): 449 - 491.

https://doi.org/10.1111/j.1467-

1770.1994.tb01114.x

[15] Gitsaki, C. (1998). Second language acquisition theories: overview and evaluation. Journal of Communication and International Studies, 4(2): 89-98.

[16] Graciá, O. (2009) Bilingual education in the 21st century, a global perspective. Malden, MA: Blackwell publishers.

[17] Hinkel, E. (2013) Research findings on teaching grammar for academic writing. English Teaching, 68(4): $3-21$.

https://doi.org/10.15858/ENG-

TEA.68.4.201312.3

[18] Hiver, P. and Dörnyei, Z. (2015) Language teacher immunity: a double-edged sword. Applied Linguistics, Advance Access, $1-20$.

[19] Krashen, S.D. (1981) Second Language Acquisition and Second Language Learning. California Pergamon Press.

[20] Krashen, S.D. (1982) Principles and practices in second language acquisition. Oxford: Pergamon Press.

[21] Krashen, S.D. (1985) The input hypothesis: Issues and implications. London: Longman Group Ltd. 
[22] Krashen, S.D. (2003) Exploration in language acquisition and use. The Taipei lecturers. Portsmouth, $\mathrm{NH}$ : Heinemann.

[23] Krashen, S.and Bland, J. (2014) Compelling Comprehensible input, Academic Language and School Libraries. CLELE Journal, 2(2): 1-12.

[24] Latifi, M.; Ketabi, S. and Mohammadi, E. (2013) The comprehension hypothesis today: an interview with Stephen Krashen. Electronic Journal of Foreign Language Teaching, 10(2): 221- 233.

[25] Lightbrown, P.M. (2000) Classroom SLA research and second language teaching. Applied Linguistics, 21 (4), 431-462.doi.10.1093/applin/21.4.431

[26] Long, M. (1996) The role of the linguistic environment in second language acquisition. In $\mathrm{W}$. Ritchie \& T. Bathia (eds.), Handbook of Second Language Acquisition, pp 413 - 468. San Diego, CA: Academic Press.

[27] McLaughlin, B. (1978) The monitor model: Some methodological considerations. Language Learning, 28: 309-332. https://doi.org/10.1111/j.14671770.1978.tb00137.x

[28] McLaughlin, B. (1991) Theories of second language acquisition. London: Arnold.

[29] Marton, W. (1990) Some remarks on the antipedagogical aspects of Krashen's Theory of second language acquisition. Studia Anglica Posnaniensia XXIII.

[30] Martin, I.M. and Ellis, N.C. (2012) The roles of phonological short -term memory and working memory in L2 grammar and vocabulary learning. Studies in Second Language Acquisition, 34 (3): 379-413. https://doi.org/10.1017/S0272263112000125

[31]Mpanza, C.D. (2018) Achieving optimal use of indigenous African languages in South Africa schooling in the wake of African Renaissance. African Renaissance, 15(2), 215-225.

[32] Mutekwa, A. (2013) The challenges of using the communicative approach (CA) in the teaching of English as a Second Language (ESL) in Zimbabwe: implications for ESL teacher Education. $A f$ rica Education Review, 10(3): 539-553. https://doi.org/10.1080/18146627.2013.853547

[33] Payne, M. (2012) Exploring Stephen Krashen “ $i+$ 1 " acquisition model in the classroom. Linguistics and Education, 22(4): 419-429. https://doi.org/10.1016/j.linged.2011.07.002.
[34] Poudel, P.P. (2019) The medium of instruction policy in Nepal: Towards critical engagement on the ideological and pedagogical debate. Journal of language and Education, 5(3), 102-110. https://doi.org/10.17323/jle.2019.8995.

[35] Saville-Troike, M. (2006) Introducing second language acquisition. Cambridge: Cambridge University Press.

[36] Schachter, J. (1988) Second language acquisition and its relationship to universal grammar. Applied Linguistics, 9(3): 219-235. https://doi.org/10.1093/applin/9.3.219

[37] Shechter, D.A. (2018) Overcoming the grammar barrier in foreign language learning: the role of television series. Journal of Language and Education, 4(2), 92-104. Doi.10/17323.2411-7390.20 18-4-2-92-104.

[38] Spada, N. and Lightbrown, P.M. (2008) Form focused instruction: isolated or integrated? TESOL Quarterly, 42 (2): 181-207. https://doi.org/10.1002/j.15457249.2008.tb00115.x

[39] Swain, M. (1985) Communicative competence: some roles of comprehensive output in its development. In S. Gass \& C. Madden, (eds.), Input and Second Language Acquisition, (pp. 235253). Rowley, M.A. Newbury House.

[40] Swain, M. (1995) Three functions of output in second language learning. In G. Cook \& B Seidehofer (eds.), Principles and practices in applied linguistics: Studies in honor of H.G. Widdowson (pp. 125 - 144). Oxford: Oxford University Press.

[41] Tricomi, E.T. (1986) Krashen's second-language acquisition theory and the teaching of edited American English. Journal of Basic Writing, 5(2): 59-69.

[42]Wheeler, G. (2003). Perspectives: Krashen, a victim of history. TESL Canada Journal, 20(2): 92-99.

[43] VanPatten, B. and Williams, J. (eds.) (2007) Theories in Second language Acquisition. New York: Routledge.

[44]Wilson, R. (2000) A summary of Stephen Krashen's "Principles and Practice in Second Language Acquisition". Language Impact.

[45]Zafar, M. (2009) Monitoring the 'Monitor': A Critique of Krashen's Five Hypotheses. The Dhaka University Journal of Linguistics, 2 (4): 139 - 146.

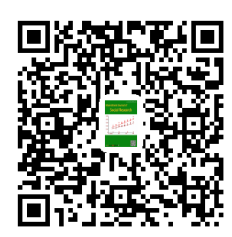

